\title{
A boa fé objetiva e os limites da rescisão unilateral dos contratos administrativos por razões de interesse público
}

\author{
Good faith and strict limits unilateral termination administrative for reasons of public \\ interest
}

Ana Laura T. Martelli ${ }^{1}$

\section{Resumo}

O presente trabalho visa discutir a prerrogativa do Poder Público em rescindir seus contratos de forma unilateral, fundamentado nas razões de interesse público. Conduzir-se-á o leitor, através de pesquisas bibliográficas e método dedutivo, à reflexão sobre a natureza jurídica da norma permissiva desta prerrogativa e sua relativização, contrapondo-a com os demais interesses envolvidos, principalmente aos do terceiro de boa-fé.

Palavras Chave: Prerrogativa; Rescisão; Unilateral; Contratos; Limites; Boa-Fé.

\section{Abstract}

This paper aims to discuss the prerogative of the Government to terminate its contracts unilaterally, based on public interest. Will lead the reader, through literature searches and deductive method, to reflect on the legal nature of the permissive rule of this prerogative and it's relativization, contrasting it with the other interests involved, especially those of third parties in good faith.

Keywords: Prerogatives; Termination; Unilateral; Contracts; Limits; Good faith.

\section{Introdução}

A Administração Pública, em razão de tutelar os interesses comuns, possui várias prerrogativas se comparada com os administrados. Entretanto, não raras vezes, o

\footnotetext{
1 Advogada e Assessora Jurídica do Município de Martinópolis/SP. Bacharel pela Faculdade de Direito da Instituição Toledo de Ensino de Presidente Prudente. Pós graduanda em Direito do Estado pela Universidade Estadual de Londrina - U.E.L.. Pós graduanda em Direito Civil e Processo Civil pela Instituição Toledo de Ensino de Presidente Prudente. E-mail: lauramartelli@adv.oabsp.org.br.
} 
administrador público utiliza-as de maneira desastrosa nas relações jurídicas contratuais, desviando a própria finalidade destes institutos.

O presente estudo, inicialmente, discorreu sobre as divergências doutrinárias existentes a respeito da nomenclatura dos contratos administrativos, bem como sua conceituação e principais características.

Em seguida, tratou de suas hipóteses de rescisão, enfatizando a modalidade unilateral em razões do interesse público e a necessidade da motivação da causa rescisória.

Finalmente, avocou-se a aplicabilidade da boa-fé objetiva e seus deveres anexos nos contratos administrativos, ocasião em que foram propostas possíveis consequências e efeitos desta aplicação.

\section{Contratos administrativos: alguns aspectos importantes}

\section{Divergências Doutrinárias Sobre o Tema}

Muito se discute a respeito da existência dos contratos administrativos, quanto sua nomenclatura, despontando sobre a divergência três grandes vertentes.

A primeira delas nega sua existência. Isto porque, para eles, o contrato administrativo, diferentemente dos demais contratos, não observa o princípio da igualdade entres as partes; ao contrário, há uma relação de verticalidade, pois a Administração se encontra em situação de supremacia em relação ao particular.

Não há que se falar também em autonomia da vontade, vista que esta se esbarra no princípio da legalidade, porquanto à Administração é dado porta-se somente com o permissivo por lei e ao particular há a sujeição às cláusulas regulamentares ou de serviço, dispostas unilateralmente por aquela.

Para esta corrente, outro elemento que firma sua conviç̧ão é a inobservância ainda da força obrigatória das convenções (pacta sunt servanda), haja vista que há a possibilidade de alteração unilateral por parte da Administração.

Assim, a ausência desses elementos que compõem a essência dos contratos, implica na inexistência e impossibilidade de configuração dos contratos administrativos.

Em contraste à primeira, a segunda posição sustenta que todos os contratos celebrados pela Administração Pública são administrativos, o que inexiste é o contrato de 
direito privado, pois toda composição em que a Administração participa há sujeição ao regime jurídico administrativo.

Desta feita, aplica-se o regime de direito público e não o direito privado, à competência, à forma, ao procedimento e à finalidade.

Adotada pela maior parte da doutrina brasileira, a terceira corrente afirma a existência dos contratos administrativos, entretanto, com características próprias e diversas do contrato de direito privado.

Nos casos em que a Administração age como Poder Público, com poder de império na relação jurídica contratual, há contrato administrativo. Caso contrário, ocorre celebração de contrato de direito privado.

Da mesma forma, será de direito público quando o negócio jurídico tiver por objeto a organização e funcionamento dos serviços públicos, for precedido por licitação e estiverem presentes as cláusulas exorbitantes ou abusivas.

A catedrática Di Pietro (2009, p. 256), adepta à terceira corrente, aceita a existência do contrato administrativo como espécie do gênero contrato e aduz que o instituto não é específico do direito privado, mas à teoria geral do direito e o classifica como contrato de direito público, que abrange contratos de direito internacional e de direito administrativo.

Para a autora, os contratos celebrados pela Administração, no que tange ao regime jurídico, classificam-se em contratos de direito privado, regidos por dispositivos do Código Civil, parcialmente derrogados por normas publicistas, como a compra e venda, doação, comodato e os contratos administrativos, que se subdividem em tipicamente administrativos, regidos inteiramente pelo direito público, como a concessão de serviço público, de obra pública e de uso de bem público e os que têm paralelo no direito privado, mas que também são regidos pelo regime jurídico administrativo, como o mandato, o empréstimo, o depósito, etc.

\section{Conceito}

A conceituação do instituto é de suma importância, pois delimita quais hipóteses se amoldam como contratos administrativos. A legislação pátria, mas especificadamente o parágrafo único do artigo 2ㅇ da Lei Regulamentadora, conceitua-o: "[..] todo e qualquer ajuste entre órgãos ou entidades da Administração Pública e particulares, em que haja 
acordo de vontade para a formação do vínculo e a estipulação de obrigações recíprocas, seja qual for a denominação utilizada."

Há vários autores que os definem, dentre eles Mello (2008, p.611) :

“[...] é um tipo de avença travada entre a Administração e terceiros na qual, por força de lei, de cláusulas pactuadas ou do tipo de objeto, a permanência do vínculo e as condições preestabelecidas assujeitam-se a cambiáveis imposições de interesse público, ressalvados os interesses patrimoniais do contratante privado".

A lei regulamentadora do instituto cuida dos contratos em sentido amplo, ou seja, todos os contratos realizados pela Administração Pública, quer sejam submetidos ao regime jurídico administrativo, quer ao regime de direito privado, chamados de contrato privado da Administração.

Portanto, alguns negócios jurídicos realizados pela Administração são regidos basilarmente pelo direito privado com interferência de algumas disposições publicistas constantes desta lei, no tocante às determinadas exigências atinentes ao procedimento prévio que o Poder Público deverá obedecer para concretizar o contrato.

Extrai-se da afirmativa, que contrato administrativo em sentido estrito consiste em convenções que a Administração é parte, sujeitas ao regime jurídico de direito público, com observância das exigências legais atinentes ao procedimento e exorbitante do direito privado.

\section{Características dos Contratos Administrativos em Sentido Estrito}

Obviamente que para constituir um contrato administrativo é imprescindível a presença da Administração Pública como uma das partes e mais, que esta atue como Poder Público.

Além disso, como é inerente a atuação do Poder Público na persecução da satisfação do interesse público, o contrato administrativo deve objetivar uma finalidade pública, sob pena de desvio de poder. 
Partindo da premissa de Rosseau, o Estado deve cumprir sua obrigação ou prestação do Contrato Social firmado com a sociedade, o que implica em sua atuação na persecução do interesse comum.

Sob o aspecto formal, os contratantes devem observar as disposições contidas na Lei no. 8.666/93, principalmente quanto à forma, pois este elemento possibilita o controle da legalidade, exercido pela própria Administração ou pelo Poder Judiciário.

A lei supracitada e outras leis esparsas vigentes, além de regulamentar a forma, que deverá ser escrita ${ }^{2}$, dispõe dentre outras coisas, a necessidade da publicação de extrato do contrato.

Assim, após 20 (vinte) dias contados da assinatura do contrato, deve ser publicado, resumidamente, um extrato do negócio no Diário Oficial.

Este rigorismo, previsto no parágrafo único, do artigo 61 da lei em comento, implica em condição de eficácia do negócio jurídico, pois enquanto não publicado o contrato não gera efeitos entre as partes.

Ademais, em regra seguinte à mencionada, o contrato formaliza-se por meio de termo ou instrumento de contrato para os casos de concorrência e de tomada de preços, bem como nos casos de dispensas e inexigibilidade de licitação.

É facultada à Administração nas demais modalidades, a formalização dos contratos através de carta contrato, nota de empenho de despesa, autorização de contrato ou ordem de execução de serviço, além do instrumento de contrato.

Quanto ao seu conteúdo, há vinculação ao instrumento convocatório da licitação, logo, este é lei do contrato e da licitação, por conseguinte não pode haver acréscimo de cláusula que não esteja prevista no edital ou carta convite, sob pena de nulidade.

Existem as cláusulas obrigatórias ou necessárias elencadas no artigo 55 da lei regulamentadora. Estas se subdividem em cláusulas regulamentares do objeto, da forma de execução, da rescisão e das responsabilidades das partes e em cláusulas financeiras, que estabelecem o equilíbrio econômico do contrato, como preço e critérios de ajustamento.

A cláusula de vigência depende da duração do respectivo crédito orçamentário, excetuando-se os casos de projetos contemplados nas metas estabelecidas no Plano Plurianual; a prestação de serviços de forma contínua, limitada a 60 (sessenta) meses e nos inferior a quatro mil reais. 
casos de aluguel de equipamentos e a utilização de programas de informática, podendo a duração estender-se pelo prazo de 48 (quarenta e oito) meses.

Importante frisar a proibição de contratos com prazo indeterminado e toda prorrogação de prazo deve ser devidamente justificada, porquanto contratos estendidos à longa data com o mesmo contratado fogem à regra do procedimento licitatório, e não asseguram a igualdade de oportunidades a outros interessados, ressalvadas as hipóteses das circunstâncias excepcionais previstas no parágrafo primeiro do artigo 57.

Outra característica importante dos contratos administrativos é que suas cláusulas são fixadas unilateralmente pela Administração.

Por esta razão a doutrina afirma que a Administração faz uma oferta aos interessados, estabelecendo as condições em que pretende contratar e a apresentação das propostas equivale à aceitação da oferta.

Tanto é assim que um dos requisitos obrigatórios do instrumento convocatório é a minuta do contrato.

Por isso alguns classificam os contratos administrativos como contratos de adesão.

Na medida da exigência legal de alguns contratos administrativos serem precedidos de licitação, tem-se sua natureza intuito personae, pois, necessariamente o interessado em contratar com a Administração Pública deverá preencher as condições objetivas previstas no edital e, após o julgamento do procedimento licitatório, o vencedor será aquele habilitado e portador da melhor proposta.

Em outras palavras, somente será contratado aquele que preencher as condições previstas no edital e estas condições levarão em conta qualidades pessoais do proponente.

Por isso o artigo 78, inciso VI, da Lei $8.666 / 93$ proíbe a subcontratação, total ou parcial, do seu objeto, a associação com outro, a cessão ou transferência, exceto quando houver previsão expressa no edital da licitação e no contrato.

Para finalizar, uma das características mais importantes dos contratos em comento, é a presença de cláusulas exorbitantes.

Como já afirmado, a Administração Pública goza de certas prerrogativas, que a coloca em posição de prevalência sobre o particular, o que possibilita a disposição de 
cláusulas exorbitantes em suas convenções, diferentemente do que ocorre no direito privado, pois tais são consideradas ilícitas e nulas de pleno direito.

Dentre estas cláusulas destacam-se a possibilidade de exigência de garantia, a alteração e rescisão unilateral do contrato, a fiscalização, aplicação de penalidades, a anulação do contrato, a retomada do objeto e a mutabilidade de suas disposições.

Todas são importantes, entretanto, discorrer-se-á sobre a possibilidade de rescisão unilateral, haja vista ser o objeto do presente trabalho.

\section{Da rescisão unilateral dos contratos administrativos}

Consta da Lei regulamentadora dos contratos administrativos, três modalidades de rescisão contratual: a amigável, a judicial e a unilateral.

Como o próprio nome sugere, a rescisão amigável é o rompimento dos efeitos do contrato derivado do acordo realizado entre as partes, dada a conveniência da ruptura para os contratantes. A judicial é aquela que geralmente é requerida pelo contratado em casos de inadimplemento da Administração.

Ambas decorrem de fatos da Administração, como a supressão de obras, serviços ou compras, acarretando modificação do valor inicial do contrato além do permitido por lei, a suspensão de sua execução por prazo superior a cento e vinte dias, salvo os casos de calamidade pública, grave perturbação da ordem interna ou guerra, atraso no pagamento pelo prazo superior a noventa dias, dentre outros casos previstos no artigo 78 , incisos XIII a XVI da Lei 8.666/93.

Finalmente, a rescisão unilateral pode se dar tanto por atos atribuíveis ao contratado, previstas nos incisos I a XI e XVIII do mesmo artigo 78, como por razões de interesse público, expressas no inciso XII.

Frise-se que em casos de inadimplemento culposo, a Administração Pública poderá aplicar ao contratado, sem prejuízo da reparação dos danos causados, sanções administrativas trazidas pelos artigos 80,86 e 87 da Lei em comento, que variam desde a retenção dos créditos decorrentes do contrato até a declaração de inidoneidade para licitar ou contratar com a Administração Pública. 
A rescisão unilateral motivada nas razões de interesse público deve ser apreciada com certa cautela, visto que não raras vezes o administrador público de forma arbitrária abusa desta prerrogativa.

Ao prever razões de interesse público de alta relevância e amplo conhecimento, a lei traz expressões vagas, imprecisas e incertas, reportando-se aos conceitos jurídicos indeterminados.

Os conceitos jurídicos indeterminados consistem naquelas expressões cujo conteúdo e extensão são incertos, carecendo de um sentido preciso e objetivo.

Segundo Enterria apud Tourinho (2008, p.2):

"Os limites destes conceitos não são traçados com exatidão pela lei, visto que não admitem uma quantificação ou determinação rigorosa. Porém, não obstante a indeterminação no conceito da hipótese da realidade, esta será determinada no momento da aplicação."

Aplicação que será exercida pelo administrador público, através da atividade interpretativa.

Os conceitos jurídicos indeterminados referem-se às normas com conceitos de valor ou experiência e como tais, poderão variar de acordo com o tempo e o espaço a depender do contexto social envolvido.

Segundo Tourinho (2008, p. 4), o critério geral para interpretação e aplicação de conceitos legais indeterminados é a opinião comum. A autora avoca ainda, a tese alemã de Bachof, segunda a qual não é concedido um espaço discricionário à autoridade administrativa quanto à aplicação dos conceitos jurídicos indeterminados, mas apenas um espaço de apreciação.

Assim, a autoridade administrativa decidirá a solução para o caso concreto segundo os valores da sociedade contemporânea, destacando, in casu, as razões de alta relevância, sempre voltada a atingir um entendimento comum, aceito pelo meio social.

Não se pode perder de vista que a extinção do contrato administrativo por razões de interesse público não envolve inadimplemento do contratado. Logo, este vem cumprindo regularmente seus deveres inerentes ao negócio jurídico. 
Segundo Marçal Filho (2010, p. 853), “A Administração promove rescisão por verificar que, por melhor que seja executado o objeto contratual, as necessidades perseguidas pelo Estado não serão satisfeitas, eis que isso somente se passará por meio de uma contratação distinta."

Destarte de um lado tem-se o interesse do particular em continuar a execução do contrato, de outro se tem a Administração Pública em rescindi-lo, sendo que a última tutela o interesse comum. Em regra, prevalece o interesse comum.

Cumpre observar que esta prevalência do interesse público não é absoluta. Diante do caso concreto cabe sua relativização, sob pena de instabilidade social e insegurança jurídica aos contratantes.

Situações de conflitos entre os direitos fundamentais, ou destes com outros bens jurídicos constitucionalmente tutelados, ou ainda, com valores constitucionais ocorrem com frequência no ordenamento jurídico brasileiro, cabendo ao intérprete sua harmonização.

Esclarece Nicolodi (2007, p. 1):

\begin{abstract}
"É através desta lente e da imperiosa concretização dos direitos em colisão que se saberá em que momento um direito prevalece sobre outro, sem, contudo, que essa imposição se faça em termos de comprimir ao máximo, de forma desnecessária, o direito do titular diverso. Necessário, portanto, que a preferência de um direito a outro se dê na estreita medida da justificação e da motivação assente na ponderação dos direitos em conflito no caso concreto".
\end{abstract}

E mais:

\begin{abstract}
"Proporcionalidade, não se esqueça, que deve servir de critério basilar para a otimização e harmonização producentes dos limites dos direitos no caso concreto, apenas em pequena medida estabelecidos pela constituição e fundamentalmente através da concordância prática, o que requer, reitera Hesse, a coordenação proporcional."
\end{abstract}

A necessidade de justificação da rescisão unilateral do contrato administrativo, fundada em razões de interesse público, além de possibilitar ao contratado o exercício do contraditório e da ampla defesa, possibilita a verificação dos interesses que se colidem e fornecem subsídios para análise de qual interesse deve sobressair-se diante do caso concreto. 
Isto sob a ótica de que o interesse público não é absoluto. Diante do caso concreto, o intérprete deverá ponderar quais os interesses conflitantes e, por intermédio do critério da proporcionalidade decidir qual irá prevalecer naquele momento, sem, contudo, comprimir o direito do outro.

Insta salientar que a prevalência de um direito sobre o outro é relativa, válida somente naquela circunstância, podendo se obter resultado diverso em outros casos concretos.

Diante disso, a rescisão não pode ser baseada unicamente em razões de relevância de interesse público, mas diante do caso concreto, estes interesses devem se sobressair aos interesses do contratado, assim considerado na opinião comum, ou o inverso a depender da harmonização, ponderação e proporcionalidade dos interesses colidentes.

Ademais, a boa fé objetiva do terceiro contratante poderá por vezes limitar as razões do interesse público em xeque.

\section{Boa-fé objetiva: Princípio e institutos relacionados}

A boa-fé objetiva, enquanto princípio, deve nortear todo o ordenamento jurídico e condicionar o comportamento das pessoas em suas relações jurídicas de forma honesta, proba e leal, prestigiando a confiança nas relações sociais.

Martins apud Pretel (2009, p. 51) define:

\footnotetext{
“O princípio da boa-fé, então, como modelo de conduta ou padrão ético que o agente deve possuir (lealdade, honestidade e etc) informa todo o ordenamento e, por consequência, tem presente em si uma função interpretativa das normas, e, pela mesma razão, uma função controladora de conduta e será critério apto para integrar as declarações de vontade (função integradora)".
}

Com efeito, o princípio da boa-fé objetiva deve orientar, inclusive, os contratos administrativos. Até mesmo porque a Administração Pública deve se submeter a outro princípio, qual seja: moralidade, que se encontra intimamente ligado ao da boa-fé.

Ademais, o princípio em estudo possui cunho constitucional, porquanto, decorre logicamente dos princípios da dignidade da pessoa humana, solidariedade e igualdade substancial. 
A doutrina destaca algumas funções da boa-fé objetiva. A primeira delas é a função interpretativa e de colmatação. Em seguida, há a função que cria deveres jurídicos anexos ou de proteção. Finalmente, tem-se a função delimitadora do exercício de direitos subjetivos.

Enquanto função interpretativa, a boa-fé objetiva exerce um papel referencial hermenêutico, a fim de se extrair da norma a solução moralmente mais recomendável e socialmente mais útil.

A função criadora ou ativa do instituto atua como fundamento normativo, ao passo que cria deveres anexos ou de proteção para as relações jurídicas. Dentre estes deveres encontram-se o dever de lealdade e confiança recíproca, de assistência, de informação e de sigilo ou confidencialidade.

A boa-fé também detém uma função delimitadora do exercício de direitos subjetivos, ou também conhecida como função controladora ou reativa, com intuito de evitar seu exercício abusivo. No dizer de Gagliano e Pamblona Filho (2006, p. 76) “(...) no atual sistema constitucional, em que se busca o desenvolvimento socioeconômico sem desvalorização da pessoa humana, não existe mais lugar para a 'tirania dos direitos' ".

As fundadas razões de interesse público que possibilitam ao administrador público a rescisão unilateral do contrato administrativo, além de justificada e motivada, deverão ser exercidas em conformidade com as regras sociais, observando a finalidade social e econômica do direito e haver legitimidade do motivo, sob pena de configurar abuso de direito.

Um ato que praticado gera um desequilíbrio injustificado entre as consequências suportadas pelas partes contratantes configura abuso de direito.

A título exemplificativo ${ }^{3}$, supõe-se um contrato administrativo firmado entre a Administração Pública e o particular com vistas ao transporte escolar de alunos do ensino fundamental, com prazo determinado de um ano, iniciando-se a vigência em 13 de abril de 2009.

Como já discorrido anteriormente, a contratação com o Poder Público é precedida de procedimento licitatório, que designará o detentor dos requisitos objetivos que autorizarão sua contratação, ou seja, o vencedor do certame disporá de uma expectativa de contratar com a Administração.

Este exemplo foi proposto em razão de experiência profissional da autora, que experimentou caso semelhante em seu ofício. 
Expectativa porque, após o decurso do prazo de interposição dos recursos administrativos tendentes a impugnar o procedimento licitatório, a autoridade administrativa verificará se ainda persistem as razões que motivaram a abertura da licitação e, em havendo homologará o procedimento e adjudicará seu objeto ao vencedor.

Pois bem. A execução do contrato que se iniciou em 13 de abril de 2009 foi interrompida unilateralmente pela Administração Pública em 08 de agosto do mesmo ano, a pretexto do interesse público, haja vista que o contratante recebeu por intermédio de convênio com outro Poder Público um ônibus escolar.

Assim, seria inviável a mantença do contrato inicial para o transporte dos alunos, sendo que a própria Administração dispunha do veículo e de motorista para executá-lo, causando um gasto desnecessário aos cofres públicos.

Saliente-se que a celebração do convênio entre os Poderes deu-se concomitantemente ao procedimento prévio da contratação (licitação) e a entrega do veículo ocorreu em 23 de março de 2009.

Ora se já havia celebração de convênio para aquisição do ônibus escolar no momento em que houve a autorização para a abertura do processo licitatório, a autoridade administrativa já agiu contrariamente ao dever de lealdade, pois não deveria sequer dar autorização para a abertura da licitação, vista que o objeto da contratação seria prejudicado com a entrega do veículo.

Ademais, ao rescindir o negócio jurídico baseado nas razões de interesse público, o administrador público abusou da sua prerrogativa, uma vez que deixou o contratado iniciar a execução do contrato mesmo já dispondo dos meios necessários para o transporte dos alunos, pois o ônibus foi entregue em 23 de março de 2009.

Ressalta-se que o administrador público, antes de homologar a licitação, possuiu a oportunidade de apreciar se persistiam as razões que ensejaram a autorização da licitação. Assim, in casu, não deveria sequer homologar o certame e adjudicar o objeto do contrato ao vencedor do procedimento, quanto mais dar início à sua execução.

Corolário ao abuso do direito, tem-se o instituto da supressio (supressão do direito ou faculdade ou a redução do seu alcance), que consiste na inércia qualificada de uma das 
partes, acarretando uma expectativa legítima à outra de que este direito ou faculdade não será exercido.

Assim, na ocasião em que o Poder Público recebeu o ônibus escolar e ainda assim, a autoridade administrativa firmou o contrato e deixou iniciar sua execução, criou-se uma expectativa legítima ao contratado de que não haveria rescisão fundada na aquisição do veículo.

Portanto, não se pode legitimar a conduta da Administração Pública desprestigiando a boa-fé do contratado que possuía uma justa expectativa de que o contrato não seria rescindido em virtude da aquisição do veículo (surrectio).

Assim, o interesse público que por vezes ampara o administrador público na tomada de decisões que interferem na esfera de direitos do particular, pode ser limitado pelo princípio da boa-fé objetiva, com seus deveres anexos e seus institutos inerentes, pois ao prestigiá-la nas relações jurídicas contratuais de direito público, também haverá atendimento do interesse público.

Isto porque é interesse coletivo que todas as relações jurídicas contratuais sejam embasadas na confiança entre as partes, honestidade, lealdade e probidade, assegurando ainda ao contratado uma sensação de segurança jurídica.

A lei estabelece o dever de ressarcimento nos casos de rescisão contratual sem culpa do contratado, entretanto, somente aqueles regularmente demonstrados e efetivamente sofridos até a data da rescisão.

Com a aplicação do princípio da boa-fé objetiva nos contratos administrativos, a sua inobservância acarretaria o dever da Administração Pública em indenizar as perdas e danos do contratado, assim entendidas os danos emergentes e os lucros cessantes ou a continuidade da execução do contrato até o término da vigência, logo, seu cumprimento integral.

Logo, o contratado de boa-fé poderia exigir o cumprimento do contrato ou o ressarcimento de seus danos efetivamente suportados, acrescidos do lucro que deixou de perceber em razão do abuso do exercício de direito e má-fé por parte da contratante (Administração Pública). 


\section{Conclusão}

A Administração Pública enquanto curadora do interesse público deve possuir prerrogativas. Entretanto, o interesse público não é absoluto.Diante do caso concreto, quando este colidir com outros direitos, o intérprete deverá ponderar quais interesses conflitantes e, por intermédio da proporcionalidade decidir aquele que (naquelas circunstâncias) deverá prevalecer.O interesse público não é aquele que a autoridade administrativa discricionariamente entende ser, mas aquele interesse assim entendido pelos padrões médios no contexto social. Logo, pode variar de acordo com o tempo e o espaço.Ademais, ainda que persistam as razões de interesse público que fundamentem a rescisão unilateral do contrato, o administrador público não pode exercer este direito de maneira abusiva e seus atos devem ser norteados pelo princípio da boa-fé, sob pena de ser compelido ao integral cumprimento do contrato ou ao pagamento das perdas e danos, assim entendidos o dano emergente e lucros cessantes.

\section{Referências}

BRASIL. Lei 8.666, de 21 de junho de 1993. Regulamenta o artigo 37, inciso XXI da Constituição Federal, institui normas para licitações e contratos da Administração Pública e dá outras providências. Diário Oficial [da] República Federativa do Brasil. Brasília, 22 jun. 1993.

BRASIL. Constituição (1988). Constituição da República Federativa do Brasil. Brasília: Senado, 1988.

DI PIETRO. Maria Sylvia Zanella. Direito administrativo. 22. ed. São Paulo: Atlas, 2009.

GAGLIANO, Pablo Stolze; PAMPLONA FILHO, Rodolfo. Novo curso de direito civil. 2. ed. São Paulo: Saraiva, 2006. v. 4.

JUSTIN FILHO, Marçal. Comentários à lei de licitações e contratos administrativos. 14. ed. São Paulo: Dialética, 2010.

MARTINS COSTA, Judith. A boa-fé no direito privado: sistema e tópica no processo obrigacional. São Paulo: Revista dos Tribunais, 2000.

MELLO, Celso Antonio Bandeira de. Curso de direito administrativo. 25. ed. São Paulo: Malheiros, 2008. 
NICOLODI, Ana Maria. Conflitos entre direitos fundamentais: liberdade de imprensa versus Direito à vida privada, direito à imagem e direito à honra. Revista Direitos Fundamentais \& Democracia, Curitiba, $\quad$ v. $1, \quad 2007 . \quad$ Disponível em:<http://revistaeletronicardfd.unibrasil.com.br>. Acesso em: 7 ago. 2010.

PRETEL, Mariana Pretel e. A boa-fé objetiva e a lealdade no processo civil brasileiro. Porto Alegre: Núria Fabris, 2009.

TOURINHO, Rita. A discricionariedade administrativa perante os conceitos jurídicos indeterminados. Revista Eletrônica de Direito do Estado, Salvador, n. 15, 2008. Disponível em: <http://direitodoestado.com.br 